\title{
Marcha Geral da Análise
}

\author{
por Alfredo Gomes*
}

SULFURETOS

( $1^{\circ}$ grupo)

Eu cá sou um sal de arsénio, Não sirvo para fazer pratos. 0 meu nome lembra logo,

A sorte que dou aos ratos.

\section{CLORETOS}

Quem me vê neste propósito,

Julga-me talvez de lata.

Sou um metal dos mais brancos,

E tenho por nome prata.

Eu sou o célebre chumbo,

Trago a desgraça comigo.

Chumbo às vezes os pardais,

E mais alguém...que não digo!

\section{III}

Eu sou um comerciante,

Mas um tanto perigoso.

Sou família do mercúrio

mas meu nome é mercuroso.

Sou o ácido clorídrico,

Tenho um cheiro impertinente.

Precipito o mercuroso,

0 chumbo e prata igualmente.

Não tenho nenhuma cor,

Mas quero ser muito franco.

Pois, quando a eles me junto, Precipito-os em branco.

\section{VI}

Eis 0 cloreto de prata, Não veio da Babilónia ? Mas para que se dissolva, Basta lançar nele amónia.

\section{VII}

Apesar de dissolvido, Inda sou muito esquisito. Deitem sobre mim azótico,

Vejam que reprecipito.

\section{VIII}

Sou o cloreto de chumbo, Conhece-me toda a gente. Quem me quiser dissolver, Empregue só água quente.

\section{IX}

A quente sou dissolvido, Mas não fico apoquentado. Se me deixam esfriar, Já estou precipitado.

\section{X}

Eis agora o mercuroso,

Que tem um tão largo emprego.

Não se dissolve na amónia,

Mas passa de branco a negro.

A amónia não o dissolve, Fá-lo negro. Que má sorte. Não faz mal. Não se incomoda, É mercúrio até a morte.

\section{II}

Eu sou o rijo antimónio, Com aplicação imensa. Pois quando ao chumbo me ligam, Faço um bom tipo de imprensa.

\section{III}

De estanho o nome tenho, Mas sou bastante teimoso. Pois posso passar de estanho, Num momento, a estanoso.

\section{IV}

Chamo-me ácido sulfídrico, E tenho um tão mau odor. Precipito, os que se seguem, Dou a todos outra cor.

\section{V}

Quando vejo um sal de arsénio Posso fazer-lhe este apelo: Tem cautela ! Pois, senão, Passas de branco a amarelo.

\section{SULFURETOS}

( $2^{\circ}$ grupo)

\section{I}

Quem não conhece o bismuto Metal de tão largo emprego? Mas o ácido sulfídrico Precipita-me de negro.

\section{II}

E depois ? Pobre de mim !

0 azótico atrevido,

Mesmo apesar de negro, Por ele sou dissolvido.

\section{III}

0 metal cobre, apesar De em dinheiro ser usado, Pelo ácido sulfídrico Dá negro precipitado.

\section{IV}

Mas o ácido azótico, Sem se importar do meu trato, De sulfureto de cobre Faz-me passar a nitrato.
VI

Se caio num sal de estanho, Sem ter a cor escarlate, Faço passar num momento 0 seu branco a chocolate.

\section{VII}

0 estânico já o sabe, Que quando the vou ao pelo, Quer ele queira, quer não Faço-o passar a amarelo.

\section{VIII}

E o antimónio ? Coitado ! P'ra que me não faça tolo, Passa a sulfureto, sim, Mas com a cor de tijolo.

\section{IX}

Ninguém se esqueça de mim, Que não sou nenhum demónio. Os três últimos dissolvo Sou o sulfureto de amónio. 


\section{POLISSULFURETOS}

I

Primeiro e segundo grupo Já lá vão. Já são passados. Vamos entrar no terceiro P'ra ver mais precepitados.

O sulfureto de amónio Vai de novo aparecer. Não vai dissolver ninguém Vai fazer escurecer.

\section{III}

Alguns que não escurecem Também sentem sua dor. A todos eu precipito, Cada um de sua cor.

\section{IV}

Comecemos pelo ferro, Para tudo aproveitado. Se se junta o sulfureto Dá negro precipitado.

\section{V}

De negro precipitado,

0 negro ninguém quer ver.

Mas o ácido clorídrico,

Trata de me dissolver.

\section{VI}

Eu sou crómio, um metal, Que não é o mais usado. Se me juntam sulfureto Dou verde precipitado.

\section{VII}

De verde precipitado, Um verde muito garrido. Juntem-me em seguida soda, E pronto. Sou dissolvido.

$$
\text { VIII }
$$

0 alumínio faz parte Deste grupo saltimbanco.

Mas com o tal sulfureto

Precipita todo branco.

\section{IX}

E agora desta cor, Não vai ser enegrecido. Mas lancemos nele a soda, Pois com ele é dissolvido.

Eu sou o róseo cobalto Pelas louças tão usado, Com sulfureto de amónio Dou negro precipitado.

\section{XI}

De negro precipitado Pelo magano atrevido. Com clorídrico e azótico Fico logo dissolvido.

\section{XII}

Pois o conhecido níquel, Que também vai ser julgado. Com sulfureto de amónio Dá negro precipitado.

\section{XIII}

Mas não fica por aqui Este tal negro obtido. Com clorídrico e azótico Como o outro é dissolvido.

\section{XIV}

Vem agora o manganês Que deste grupo é irmão. Com sulfureto de amónio Tomou a cor de salmão.XV De salmão precipitado, Cor que agrada a toda a gente. Mas o ácido clorídrico Dissolve-o num repente.

\section{XVI}

É um metal muito brando 0 pobre zinco coitado. Com sulfureto de amónio Dá branco precipitado.

\section{METAIS ALCALINO-TERROSOS}

Entremos no quarto grupo, Que é um dos mais engraçados. Com carbonato de amónio, Também dão precipitados.

Lançando água de gesso,

0 estrôncio se conhece.

Esperando alguns instantes Precipitado aparece.

\section{III}

O bário é semelhante,

Mas já, não tão lentamente. Lançando a dita água Dá precipitado rapidamente.

\section{IV}

P'ra precipitar o cálcio,

Não é nenhuma charada.

Mas com água de gesso,

Nunca mais nos dará nada.

\section{V}

Mas enfim. Antes que custe, Mesmo que leve um bocado. Com oxalato de amónio Dá logo precipitado.

\section{VI}

Entre no quinto grupo, Agora vai de enfiada. Com quatro quadras mais Está a marcha acabada.

\section{VII}

Tenho magnésio por nome, Que nome tão esquisito. Mas se me juntam fosfato, Num momento precipito.

\section{VIII}

A mim chamam-me potássio, Tantos sabonetes dou, Mas depressa precipito Com o célebre Carnot.

\section{IX}

Sódio. Que lindo nome, Mas que nome tão sensato. Sou precipitado com Piro-antimoniato.

\section{X}

P'ro amónio conhecer, Basta soda lhe juntar. Se a mistura se aquecer A amónia há-de cheirar. 


\section{ANIÕES}

I

Outro trabalho vamos ter, Para decorar os aniões,

Visto já termos passado

0 grupo dos catiões.

\section{II}

Serão estes divididos

Em quatro grupos, afinal.

Sulfídrico, cloro e fosfórico

E azótico matinal.

\section{III}

Para conhecer os sulfatos,

Levamos a cruz ao calvário.

Não dá precipitado pela prata,

Mas dá precipitado pelo bário.

\section{IV}

Para não ficarmos em dúvida, Com o sulfato atrevido, Precipita pelo chumbo, Pela soda é dissolvido.

\section{V}

Entramos no segundo grupo, Só um precipitado é preto. Não, o cloro, bromo e iodo, Mas sim o sulfureto.

VI

Ao contrário dos sulfatos, Olhem para este fadário. Precipita pela prata, Não se importa com o bário.

\section{VII}

De uma vez, três se apanham, E para melhor os conhecer Com manganês e sulfúrico Depois é só aquecer.
VIII

0 primeiro cheira a cloro,

0 seu cheiro é verídico.

Quem não o há-de conhecer.

Na presença, o clorídrico.

\section{IX}

O segundo é violáceo, Um violeta ametista. Quem não conhece o iodo Na sua cor característica.

0 terceiro, alaranjado, Um alaranjado qualquer. Trata-se do simples bromo Na lei de Lavoisier.

\section{XI}

Agora o sulfídrico Que tem tão mau odor. Conhece-se pelo cheiro, Pois não tem outra cor.

\section{XII}

Para melhor o verificar, Desta maneira se cnhece. Papel de acetato de chumbo Pelo dito ácido enegrece.

\section{XIII}

Estamos no terceiro grupo, Este é o mais engraçado. Juntando-lhe prata ou bário Dá com ambos precipitado.

\section{XIV}

É o grupo do fosfórico, Fosfórico ou fosfatos. Também tem arseniatos, Cromatos e carbonatos.

\section{$\mathrm{XV}$}

Para conhecer o fosfórico,

Fosfórico ou fosfatos.

Dá precipitado amarelo

Com nitromolibdato.

\section{XVI}

Agora 0 arseniato,

Para que não se faça tolo.

Precipita com a prata

Com uma cor de tijolo.

\section{XVII}

Na mesma cor de tijolo,

0 cromato se desvela.

Mas distingue-se no soluto

Por ter uma cor amarela

\section{XVIII}

Temos agora os carbonatos, Que se trata por eminência. Se lhes juntar-mos clorídrico Dá com eles efervescência.

\section{XIX}

Por último o quarto grupo, Que tem s sua piada.

Ao juntar-lhe prata ou bário, Nunca mais nos dará nada.

\section{$\mathrm{XX}$}

Também temos os nitratos, Com seus ares fanfarrantes. Ao juntar sulfúrico e cobre Dá-nos vapores rutilantes.

\section{XXI}

E pronto, meus amiguinhos, Quem os versos decorou Não perdeu o seu tempo, Mas alguma coisa ganhou.

* O Sr. Alfredo Gomes, nascido na Ajuda, Lisboa, a 14 de Maio de 1901, foi funcionário do Laboratório de Química da Escola Politécnica (actual Faculdade de Ciências da Universidade de Lisboa) e, pelos vistos, era também poeta. A Marcha Geral da Análise é um trabalho da sua autoria, escrito em 1953. A publicação deste poema no Química foi possível graças à amabilidade do Doutor António Morais Romão Serralheiro, professor catedrático jubilado do Departamento de Geologia da FCUL, que recolheu o manuscrito e o mostrou, depois de dactilografado, a um sócio da SPQ. Para o Doutor António Serralheiro vão os nossos agradecimentos. 